\title{
"We cannot stop cooking": Stove stacking, seasonality and the risky practices of household cookstove transitions in Nigeria
}

\author{
Sarah Jewitt ${ }^{\mathrm{a}, *}$, Peter Atagher ${ }^{\mathrm{b}}$, Mike Clifford ${ }^{\mathrm{b}}$ \\ ${ }^{a}$ School of Geography, University of Nottingham, University Park, Nottingham NG7 2RD, United Kingdom \\ ${ }^{\mathrm{b}}$ Faculty of Engineering, University of Nottingham, University Park, Nottingham NG7 2RD, United Kingdom
}

\section{A R T I C L E I N F O}

\section{Keywords:}

Fuelwood

Energy ladder

Backsliding

Risk

Household air pollution

Benue state

\begin{abstract}
A B S T R A C T
Drawing on qualitative data from three contrasting sites in Benue state, Nigeria, this paper explores how and why cooking system use and priorities vary over time and space as well as the influence of household air pollution (HAP)-related health risks on fuel and stove choices. The findings indicated that cooking system choices were constrained by economic and access considerations linked to spatio-temporal variations in fuel cost, availability and service quality coupled with socio-cultural and utilitarian influences on cooking practices. Respondents demonstrated strong preferences for wood-fuelled traditional stoves although shifts in fuel use between wet and dry seasons were observed. Stove and fuel 'stacking' were widely practised to meet different cooking requirements and minimise risks from (often seasonal) variations in fuel prices, access and reliability of supply. 'Backsliding' from clean to solid biomass fuels was observed when families outgrew their improved cookstoves or considered biomass to be more affordable, reliable, accessible or safer. There was limited awareness or concern about HAP-related health risks and smoke was valued for preserving food and signalling food security. Attention is drawn to the value of integrating household risk perceptions into improved cookstove promotion and behaviour change initiatives to better understand constraints to the adoption and sustained use of clean cooking systems. The paper concludes by highlighting the benefits of monitoring household cooking system stacks (rather than the 'main' fuel/stove used) for analysing how their components vary over space and time and providing insights into the effectiveness of measures taken to reduce HAP exposure.
\end{abstract}

\section{Introduction}

Heart disease, childhood pneumonia, chronic respiratory diseases, cancers, burns and cataracts are all linked to the use of traditional cookstoves burning solid biomass fuels which are used by around 3 billion people globally [1]. In Nigeria, cooking accounts for $91 \%$ of total domestic energy consumption [2] and wood is the most widely utilised cooking fuel with 120 million Nigerians estimated to be vulnerable to illness and deaths from exposure to cooking smoke [3]. Household air pollution (HAP) from inefficient stoves fuelled with biomass, kerosene or coal is thought to cause 4 million deaths yearly [1]. Women and children often suffer greater exposure as prevailing gender norms tend to give them greater responsibility for food preparation $[1,4,5]$. In addition to these health impacts, the use of unsustainably harvested biomass fuel for cooking has been linked to forest degradation while soot from incomplete biomass combustion contributes to black carbon emissions and global warming $[4,6]$.

Recognising that biomass will remain an important source of cooking and heating energy for decades to come [7], the Global Alliance for Clean Cookstoves (GACC) was established in 2010 with the aim 'to foster the adoption of clean cookstoves and fuels in 100 million households by $2020^{\prime}$ [8]. In October 2018, GACC changed its name to the Clean Cooking Alliance (CCA); acknowledging the importance of increasing access to 'clean' cooking systems (CCS), rather than just stoves, in order to address HAP-related health and environmental problems [9]. This has been accompanied by emphasis on increasing investment in the clean cooking sector, developing programs to raise demand for CCS and improving the policy environment; strategies that mark a departure from more classic hardware-oriented-initiatives that have been criticised for failing to consider end-user priorities $[9,10]$.

Alongside CCA's activities, Sustainable Energy for All (SE4ALL) in collaboration with IEA, the World Bank and the Energy Sector Management Assistance Program (ESMAP) drafted energy-related targets and indicators for inclusion in the Sustainable Development Goals (SDGs). Target 7.1.2 seeks 'universal access to clean fuels and technologies for cooking' and tracks the 'proportion of the population with

\footnotetext{
* Corresponding author.

E-mail addresses: sarah.jewitt@nottingham.ac.uk (S. Jewitt), eaxpa@exmail.nottingham.ac.uk (P. Atagher), mike.clifford@nottingham.ac.uk (M. Clifford).
} 
primary reliance on clean fuels and technologies' but progress towards this is lagging and has barely kept pace with population increase [1]. Efforts to explain this have focused primarily on barriers to the initial adoption of CCS [12] yet, as Rosenthal et al. [13] point out, there is a need to better understand why biomass fuel use persists even when clean cooking solutions are available (and often affordable). Households that adopt CCS often continue to use their existing stoves ('stacking') both to meet diverse cooking needs (a fairly universal requirement) and address more specific deficiencies in energy access or stove characteristics [14-17]. More serious is a tendency for families to abandon CCS and revert ('backslide') to biomass-fuelled cookstoves [14]; behaviour that echoes concerns about the sustained use of improved sanitation systems as it undermines the health benefits associated with sustained and exclusive use of 'improved' technologies $[9,18,19]$. A need has therefore been identified for better understandings of how user-based and socio-cultural influences on cooking practice [20-23] interact with existing energy services to not only influence CCS uptake but also their sustained use [12,24,25].

Building on these studies, this paper draws on research with (primarily) biomass fuel users in three contrasting sites within Benue state Nigeria. Our research questions focus on the interplay of socio-cultural systems and energy services (including stove/fuel characteristics) as influences on fuel/stove use, how this affects fuel/stove stack composition over space and time and the extent to which knowledge or concerns about HAP-related risks affect fuel/stove use. The paper is informed by the careful use of a range of 'human-centred' [26], primarily qualitative approaches to explore how and why cooking system combinations vary over space and time, interpret meanings attached to fuel/stove choices and understand how they are perceived in relation to other household priorities. Its novelty lies in its focus on shifts in the composition of cooking system stacks (rather than on individual fuels or stoves) and its contributions to existing conceptualisations of key barriers to and enablers for energy transitions among biomass users $[10,26,27]$. A key theme arising from our findings is how context-specific end-user priorities plus spatio-temporal variations in the cost, accessibility and reliability of modern energy services combine to promote risk minimising behaviour that can inhibit the sustained use of a single CCS. These insights, along with understandings of how individuals perceive HAP-related risks and prioritise ICS in relation to competing financial priorities, have relevance for policy-makers as well as for tracking access to clean cooking solutions and promoting the development of approaches that support their uptake and sustained use [26].

A review of key literature is provided in Section 2 where, drawing from our empirical findings, we also outline the value of considering end-user risk perceptions as an influence on the uptake and sustained use of CCS. In Section 3.1, an overview of the study site locations is provided while Section 3.2 describes the methodological approach. Section 4 sets out the key findings and is divided into four parts. Details on household fuel/stove use are provided in Sections 4.1 while 4.2 identifies how cooking system choices reflect a combination of sociocultural and more utilitarian factors. The influence of economic considerations is explored in 4.3 while 4.4 focuses on issues of fuel access and quality of service. A discussion and a conclusion to the paper are provided in Sections 5 and 6.

\section{Literature review}

A range of models and theoretical approaches have been developed to elucidate factors that encourage (or hinder) CCS adoption. One of the most longstanding is the 'energy ladder' model which assumes that increasing socio-economic status is accompanied by a linear shift from biomass-fuelled traditional stoves to cleaner, more efficient cooking systems $[28,29]$. There is inconsistent evidence for such a pattern as while low socio-economic status is often important in preventing CCS adoption, it is often not the main or only constraint. In the cookstove literature, key barriers to CCS adoption tend to fall within three broad groups; namely economic influences, access and availability/infrastructural factors and socio-cultural considerations [14,20,21,22,3033]. In addition to constraining CCS adoption, many of these barriers have also been linked to the frequently non-linear nature of CCS transitions including the stacking of clean, transitional (e.g. kerosene or biogas) and biomass fuels and the abandonment of clean fuels in favour of biomass [12,14,20,24,34].

With respect to economic influences (broadly defined), initial stove costs coupled with ongoing fuel payments often deter uptake; especially for those with competing economic priorities or using zero-cost fuels or stoves [1,10,14,20,21,34-39]. Among those who adopt CCS, fuel price rises or unaffordable ongoing fuel costs can encourage stacking or backsliding; especially where zero-cost biomass is available $[1,12,14,21,22,34-36,40]$. As influences on both CCS uptake and stacking/backsliding, economic factors are therefore often intersected by access-related issues including the availability of free biomass at one end of the spectrum and infrastructure for reliable and affordable CCS access at the other $[1,14,20-22,24,32,34,35,37,40,41]$. Spatio-temporal variations in fuel requirements, availability, access and quality can also promote stacking [12,14,24,34,36,42].

With respect to socio-cultural considerations, CCS adoption and sustained use can be inhibited by inertia-inducing influences including taste preferences, [12,21,24,32] and religious customs surrounding stove/fuel use [20,32,43]. Culturally-constructed gender norms that give women responsibility for cooking and fuel collection but deny them control over household budgets may also limit CCS transitions $[5,31,36,39,42,44,45]$. By contrast, other socio-cultural factors can help promote CCS adoption including their aspirational appeal [12], associations between ritual purity and clean kitchens/pots [32] and challenges to gendered household decision-making by more educated or financially independent women [12,20,39]. Such influences highlight the duality of agency and structure [46] and illustrate how complex stove/fuel choices and the 'practice' of cooking reflect both selfinterest and socially-motivated factors [20,21,22,24].

Reflecting this, efforts have been made to identify and adapt behaviour change models to counter inertia and promote sustained transitions to CCS $[12,34,47]$. Some of these effectively highlight more utilitarian end-user preferences for traditional cooking systems that often underpin both stacking and low motivation for CCS uptake $[9,12,47]$ but receive less attention than the three main groups of barriers mentioned above. Examples include perceptions of traditional stoves as durable $[10,12,31,34,42]$, easy to fuel $[10,12,31,40]$ and ideal for cooking particular foods [25,31,32] or large meals [12,34,39,42]. Also, and in stark contrast to global concerns about HAP-related health problems, biomass smoke is often greatly valued by end-users for preserving food and deterring mosquitoes [10,31].

These observations often reflect end-users' limited awareness of HAP-related health risks $[10,31]$, but even when this is not so, health concerns rarely drive cooking technology transitions [9,20,32] and are often overshadowed by more immediate priorities that cut across the three main barrier groups. Examples include backsliding to or stacking biomass fuels to reduce the risk of not being able to cook when faced with fuel shortages or price rises [12,14]. CCS-related safety concerns can also shape the practice of cooking within a community; especially where significant incidents are known to have occurred [20-22]. This has been observed where LPG explosions and leakages have deterred uptake and caused backsliding [20,21,31,34,40].

Knowing how different risks are perceived at societal as well as individual levels can therefore add significant insights into cooking as practice [20-22]. To date, however, risk-related research has received limited attention in relation to CCS; despite being used to explore perceptions of energy-related issues as diverse as electricity transmission infrastructure, non-conventional renewables and interlinkages between energy security and health $[48,49,50]$. To this end, we highlight the contribution that a closer focus on cooking-related risk 


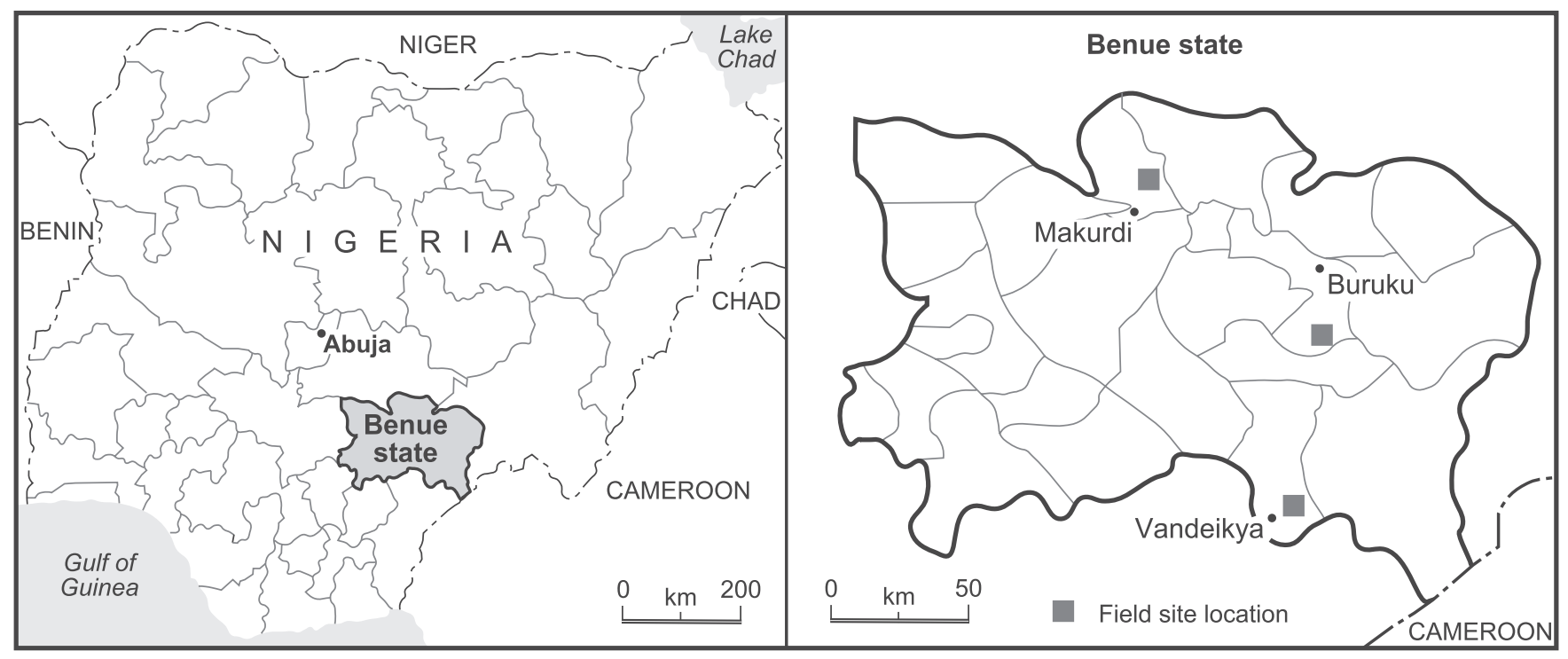

Fig. 1. Map of the study sites within Benue state.

perceptions could have to this field. In particular, the ways in which different risks are 'foregrounded' or 'backgrounded' [51] can offer insights into decision-making by low income groups preoccupied with meeting basic subsistence needs $[10,11,52]$. At the same time, the risk and environmental risk transition models [53,54] provide useful context for exploring spatio-temporal risk perceptions in response to shifts in mortality and disease patterns and their environmental influences. Given the influence of the energy ladder model in CCS-related research, the intersection of risk perceptions with socio-economic status has potential to elucidate how priority is given to different risks/hazards according to their spatial or temporal proximity. Amongst groups whose everyday lives are dominated by hazards linked to food insecurity, disease and high infant mortality, for example, temporally distant, complex risks such as HAP with poorly understood cause-effect relationships are likely to be backgrounded $[10,11]$. Understanding how such risk perceptions intersect with social norms and available fuel/ stove combinations to influence cooking practice at both individual and community levels are therefore likely to be of value for initiatives seeking to promote and sustain clean energy transitions.

\section{Study location and methodological approach}

\subsection{Study site location and context}

The field-based research was undertaken in a Tiv-dominated area of Benue state (BS) in North Central Nigeria (see Fig. 1). Analysis of data on the main cooking fuels used in the 2008, 2010, 2013 and $2015 \mathrm{Ni}$ gerian Demographic Health Surveys highlighted Benue as a good study location on account of its high dependence on biomass fuel and pronounced rural-urban variations in the use of alternative fuels such as kerosene, charcoal, electricity and LPG. An additional influence was Atagher's familiarity with local socio-economic and cultural norms and ability to speak Tiv which helped in gaining access to local community members and building trust.

Three sites within BS were chosen for study based on their contrasting fuel use and access to energy infrastructure. They are referred to by codes instead of place names in line with assurances of anonymity provided to participants. The first site, located in an urban community (BS-U) within the state capital, had good access to modern fuels (typically around $120 \mathrm{~h}$ /week of electricity supply plus a range of LPG refilling outlets) along with charcoal and fuelwood. As such, it provided useful insights into the value attached to ICS and modern fuels compared to more 'traditional' cooking systems typically comprising of
Table 1

Main fuel used by sample households in the three study sites.

\begin{tabular}{lllll}
\hline Urban & $\begin{array}{l}\text { Urban\% } \\
\text { (count) }\end{array}$ & $\begin{array}{l}\text { Semi-urban\% } \\
\text { (count) }\end{array}$ & $\begin{array}{l}\text { Rural\% } \\
\text { (count) }\end{array}$ & $\begin{array}{l}\text { Total\% } \\
\text { (count) }\end{array}$ \\
\hline Firewood & $43(3)$ & $57(4)$ & $86(6)$ & $61(13)$ \\
Charcoal & $14(1)$ & $14(1)$ & 0 & $10(2)$ \\
Kerosene & $14(1)$ & $14(1)$ & 0 & $10(2)$ \\
Electricity & $14(1)$ & 0 & 0 & $5(1)$ \\
LPG & $14(1)$ & $14(1)$ & $14(1)$ & $14(3)$ \\
\hline
\end{tabular}

wood-fuelled three stone fires (WFTSFs). The second site, located in a peri-urban area (BS-PU), was characterised by a reliance on fuelwood as the primary cooking fuel. Households that couldn't afford to purchase firewood travelled several kilometres to gather it free of cost as local woodlands had been exhausted. Electricity was available in this site for only around $18 \mathrm{~h}$ /week. The third site, a rural community (BS-R), had access to state-managed plantations from which households gathered firewood for cooking. Livelihoods here were dominated by trading and farm produce processing with access to electricity on a par with that in BR-PU.

A greater proportion of households in BS-U (86\%) had electricity connections than in BS-PU and BS-R (43\% and 14\% respectively) which they used mainly for lighting rather than cooking (see Table 1). Solar lighting was also used; especially in BS-U. Although electricity subsidies meant that tariffs were below the prices charged by generating companies [55], concern about the overestimation of bills by electricity distribution companies had deterred some households from paying for connections. This was particularly so in BS-U and BS-PU where fewer meters were available. Reflecting the situation for Nigeria as a whole [56], LPG was not widely used for cooking. Unlike LPG, kerosene was subsidised [57] for most of the fieldwork period ${ }^{1}$ but was rarely available at the official price and kerosene stove use declined from the late 2000s. Echoing studies elsewhere [20,21,31,34,40,60], concerns about the risk of explosions were expressed in relation to both fuels and kerosene was associated with serious burn injuries.

\footnotetext{
${ }^{1}$ In January 2016, petroleum product subsidies were removed and the government approved kerosene price rose from US $\$ 0.25$ to 0.41 but when oil prices rose in mid-2016, official kerosene prices remained stable, implying 'the return of an implicit subsidy' [58:1]. More recently, moves have been made to remove VAT on locally-produced LPG [59].
} 


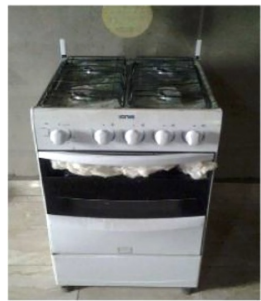

gas cooker

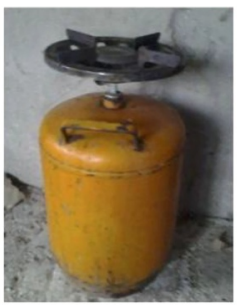

gas stove electric cooker
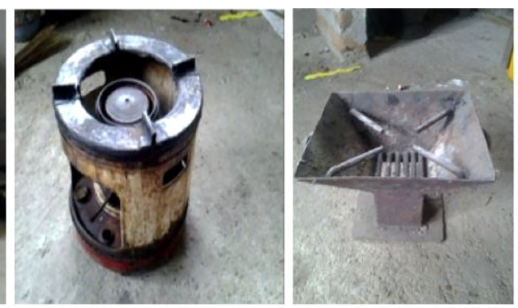

kerosene stove Abacha stove

Fig. 2. Different stoves used in the study sites.

\subsection{Data collection and analysis}

Fieldwork in Benue took place between March 2015 and May 2016 although contact with the study communities is ongoing. Echoing similar studies elsewhere in Nigeria [10] access to community members was obtained via chiefs who acted as gatekeepers and assisted in the purposive selection of male and female participants from different socio-economic groups and with access to a range of stove/fuel combinations. To capture the perspectives of female respondents and minimise potential discomfort about being approached by a male researcher, a female Tiv research assistant was employed to work alongside Atagher. All participants gave informed consent before taking part in the research and their names were anonymised in line with ethical approval obtained in advance of the study.

In response to calls for improved understandings of how cultural dynamics drive household stove and fuel choices [16,26], qualitative techniques were used to explore research questions on factors influencing the use of (and temporal shifts between) different cooking stack components along with spatial variations in stack composition. Questions regarding respondents' awareness of HAP-related health problems and their influence on stove/fuel use along with discussions on broader perceptions of risk and socio-economic priorities were investigated using qualitative methods. Focus group discussions (FGDs) and participatory exercises were carried out with 49 (14 male, 35 female) participants to identify stove/fuel use and preferences in the different sites with ranking exercises chosen as a means to identify where stove and fuel choice sat within broader household priorities and aspirations. The fieldwork also involved direct and participant observation of cooking activities in each site. Semi-structured interviews were undertaken with 3 community elders in each site ( 6 female and 3 male) to elicit information on changes in cooking practices over time.

Questions relating to spatial variations in energy access and the influence of household demographics and kitchen layout on stove/fuel stack components were addressed with the use of household surveys undertaken with 21 participants recruited during the FGDs; 7 at each site. These surveys contained open and closed questions and sought to complement the qualitative methods in enhancing understandings of variations in stove/fuel use, including stoves that were no longer in use and the reasons for this. The overall sample size (survey plus qualitative methods) was influenced by a desire to inductively analyse and interpret differences between the three sites rather than to produce generalisable results [61]. Qualitative data derived from these methods were translated from Tiv, transcribed, exported into NVivo 10, coded and analysed thematically with meanings and interpretations being cross-checked among the research team [61]. Quantitative data from the surveys were coded in Microsoft Excel and analysed using simple descriptive statistics.

Although fieldwork conducted by Nigerian researchers from the same ethnic group helped to provide 'insider' perspectives that were useful in informing the research [10] we acknowledge that their education and economic security simultaneously marked them out as 'outsiders' and may have encouraged some social desirability bias [62].
We attempted to minimise the effects of this by using observational approaches in combination with interviews, FGDs and surveys during the course of the fieldwork. Other limitations include the danger of misinterpreting meanings during interviews or translation [61], silencing less dominant voices due to FGD composition or dynamics and missing nuances during coding due to the fast-paced nature of the FGDs [63]. In order to elicit the views of quieter FGD participants, efforts were made to speak privately to them on a different occasion. To minimise misinterpretation and the loss of nuance, Atagher and his research assistant compared notes taken during FGDs to cross-check their understandings of the issues under discussion and fill in any gaps. Transcribed interviews were also shared for cross-checking while translations were checked and clarified by the co-authors.

\section{Findings}

\subsection{Household fuel use}

The cooking systems used by respondents in the study sites formed a spectrum from WFTSFs through slightly cleaner charcoal and transitional kerosene stoves to 'clean' gas and electric cookers (see Fig. 2). Echoing SDG7.1.2's emphasis on tracking 'primary reliance on clean fuels and technologies', questions about the main fuel used revealed that 13 of the 21 sample households $(61 \%)$ relied on wood (see Table 1). Some rural-urban variations were noted with firewood being used more widely in BS-R than in BS-U and BS-PU where more fuel options were present. One BS-U household used electricity as their main cooking fuel and two (one in BS-U and one in BS-PU) used kerosene. LPG was not widely used on the whole although three households (one in each site) reported it as their primary cooking fuel. Charcoal was more prevalent with one sample household in BS-U and BS-PU using it as their primary fuel and a few reporting good incomes from selling it. It was most commonly burned on rudimentary metal 'Abacha' stoves ${ }^{2}$ which our respondents referred to as 'improved' (compared to WFTSFs) although they likely offer insignificant improvements in either fuel-efficiency or smoke reduction.

As discussions with respondents made clear, however, our questions on the main fuel used revealed only a partial picture as most used a stack of fuel/stove combinations to meet their cooking needs (see Table 2). Echoing studies in many other areas [12,14-17,22,24,31,32] wood was widely used in combination with clean (or cleaner) fuels in all three sites. In BS-U, many households retained WFTSFs and demand for firewood was such that some households purchased it for re-sale within the community. In BS-R, WFTSFs were most commonly used but many respondents made sparing use of kerosene (sometimes just for

\footnotetext{
2 'Abacha' stoves became widespread following kerosene shortages during the time of Sani Abacha; a military dictator who served as the President of Nigeria from 1993 until his death in 1998. Since then, they have been widely produced and there are many different types available. Initially, Abacha stoves were used to burn any available fuel but our respondents were referring to locally made charcoal-burning stoves (see Fig. 2).
} 
Table 2

Total number of stoves used by households in the study sites.

\begin{tabular}{lllll}
\hline & $\begin{array}{l}\text { Urban\% } \\
\text { (count) }\end{array}$ & $\begin{array}{l}\text { Semi-urban\% } \\
\text { (count) }\end{array}$ & $\begin{array}{l}\text { Rural\% } \\
\text { (count) }\end{array}$ & $\begin{array}{l}\text { Total\% } \\
\text { (count) }\end{array}$ \\
\hline Three stone fire & $23.8(5)$ & $33(7)$ & $33(7)$ & $90.4(19)$ \\
Abacha stove & $19(4)$ & $14.2(3)$ & $23.8(5)$ & $57(12)$ \\
Kerosene stove & $23.8(5)$ & $19(4)$ & $14.2(3)$ & $57(12)$ \\
Electric stove & $9.52(2)$ & $4.76(1)$ & $4.76(1)$ & $19(4)$ \\
LPG stove & $14.2(3)$ & $9.52(2)$ & $14.2(3)$ & $38(8)$ \\
\hline
\end{tabular}

lighting their fires) and some used charcoal- and LPG-fuelled systems. Although 12 electric and gas stoves were used by our sample households, none relied solely on CCS.

During discussions about the make-up of household cooking system stacks, it became clear that temporary - often seasonal - shifts between stack components were common in all three sites. Sometimes this restacking resulted in cleaner stove/fuel combinations but both short and longer term 'backsliding' to more polluting systems were also observed. Coding of the qualitative data highlighted three main sets of explanations for these shifts which focused around user-based priorities linked to a mixture of pragmatic and socio-cultural factors, economic constraints and issues relating to access and poor quality of service. These proved useful in identifying key barriers to both the adoption and sustained use of clean fuel/stove combinations - as either primary cooking systems or components of cleaner stacks - and are explored in the following 3 sections.

\subsection{The influence of user-based cooking priorities linked to utilitarian and socio-cultural factors}

Utilitarian and socio-cultural factors had an important influence on how users prioritised particular cooking systems and the value placed on WFTSFs was clearly apparent in all three sites, helping to explain low levels of demand for CCS. Echoing research elsewhere in Nigeria [10], respondents emphasised the benefits of wood smoke for adding flavour to food and also preserving it in the absence of either refrigerators or a reliable and affordable supply of electricity to power them:

“...on the three-stone fire we use firewood as the main fuel for cooking and sometimes for preserving meat...you cannot use another stove for meat preservation, so when it comes to that...firewood and the threestone fire is utilized to give the meat an accentuated aroma that is highly appreciated. If I had a gas stove, I would still use firewood to preserve my meat because it is very important to the family"

(Male. Interview. BS-U).

Perceptions that wood 'cooks faster than any other fuel' also encouraged WFTSF use; especially when food needed to be cooked in a hurry such as when household members returned hungry from the fields. During our observation of cooking activities in the study sites, cooks explained that they could quickly increase the heat by adding more wood, helping to perpetuate the belief that traditional stoves cook quickly:

“... with my three-stone fire I put in as much firewood as I can to enable my meals to cook faster"

(Male. FGD. BS-U).

The fact that fuelwood could be added to three stone fires with minimal preparation (unlike many cleaner burning biomass stoves which require wood to be chopped into small pieces) was particularly valued along with the ability to keep the cooking pot in place whilst refuelling. During FGDs, respondents explained that as it is considered culturally inappropriate to remove a pot from the flame during cooking, many improved biomass (including Abacha) stoves were disliked for requiring this: "...what I do not like about the stove is the process of feeding in fuel which is carried out in a manner that reflects a typical traditional ritual. The practice is uncustomary, a pot is usually brought down from the stove before charcoal is fed into the combustion chamber...I personally know of some places where people, especially strangers, hardly eat meals that are prepared on the stove"

(Female. Interview. BS-U).

WFTSFs were also liked for their capacity to cook large meals; an important attribute in Tiv communities where 'ethnic specific' [10] cultural norms associate cooking large quantities of food with higher socio-economic status. Tiv respondents also preferred smoke-producing stoves as they made clear visual statements that there was enough food to give to a visitor. Linked to this was the ease with which WFTSFs could be adapted to accept larger cooking pots for special events:

“...during cultural festivals... a gas stove cannot satisfy the demand of the people present...that is why we use big pots on the three stone fireplace because these traditional stoves can withstand the large sizes of our cooking pots"

(Female elder. Interview. BS-U).

This was an important theme in all FGDs as respondents pointed out that the food requirements of larger households could not easily be accommodated on most improved stoves:

"I believe there is no stove that would accommodate the quantity of food I cook in my household except my three stone fireplace...stoves like gas, electric, kerosene and Abacha would not help out...so I prepare the three stone fireplace and purchase enough firewood for all my cooking activities...even if I have a gas stove, the quantity of food that is needed in my household cannot be prepared on such a stove...not possible"

(Female elder. Interview. BS-PU).

Indeed, this appeared to be an important cause of long-term backsliding in the study sites as families 'outgrew' their improved stoves and reverted to WFTSFs:

"I have stopped using my kerosene stove since my family size is now large and I have gone back to my traditional three-stone fire since it can cook the desired quantity of meals at once"

(Female. FGD. BS-U).

Other explanations for backsliding from kerosene and caution in using LPG reflect fears about the risk of burns and explosions (with one respondent having witnessed a kerosene stove exploding at a neighbour's house) coupled with a dislike of the smoke they produce:

"I think it is the smokiest stove I have ever used...we are done with the stove"

(Male elder. Interview. BS-U).

Although strong user preferences for WFTSFs were prevalent in all three sites, there was widespread agreement that one cooking device was insufficient to meet all household requirements. Echoing research elsewhere [10,12,14-17,22,24,32], FGDs revealed a combination of practical and socio-cultural reasons for stacking a range of fuel/stove combinations. The ability to cook different foods simultaneously was highlighted as particularly desirable so households without multiburner stoves used more than one system for preparing larger meals or foods with different cooking requirements:

“...the three-stone fire [is used] for preparing large quantities of food while the kerosene stove is for soup only"

(Female. FGD. BS-U).

As is common in other areas with pronounced seasonal weather patterns [12,24,34], cooking system choices varied between the dry and wet seasons with short-term shifts up the energy ladder often occurring during the rains in response to increased smoke production from burning wet wood: 
"In the rainy season, I use my kerosene stove because firewood is usually wet, so it produces a lot of smoke. I don"t use my three-stone fire during this time"

(Female. FGD. BS-U).

One respondent reported having purchased a new stove as a result of his wife's smoke-related health problems:

“...my wife ... was experiencing pains in her eyes and when I took her to the hospital, I ended up spending so much money such that I have no savings again. Since then if she makes a demand in the kitchen, I quickly respond to it ... unless I don"t have [the means to do so]"

(Male. FGD. BS-R).

Additional reasons favouring the use of cleaner stoves from household cooking stacks during the rains include difficulties associated with keeping stored wood dry, lighting wet wood and the impracticality of moving WFTSFs to drier or indoor locations. With these factors in mind and reflecting a tendency for men to control household budgets in the study area, as elsewhere [5,10,20,21], FGDs revealed that the wet season was a time when women often asked their husbands to purchase improved cookstoves. In most cases they were referring to Abacha stoves which they perceived as relatively inexpensive and cleaner in the sense that they produced less smoke and helped reduce drudgery associated with keeping kitchens and cooking pots clean:

“...since I have been using the Abacha stove, my cooking pots have remained clean, but the three-stone fire produces a lot of smoke and dirt ... you don"t experience that with Abacha stoves"

(Female, FGD. BS-U).

“...three stone fires and firewood smoke make the kitchen look untidy including the cooking pots"

(Female elder. Interview. BS-R).

The onset of the rainy season therefore acted as an enabler for shifts to slightly cleaner cooking stacks whilst also encouraging householdand community-level reflection on the health risks of WFTSFs. The discomfort of smoke generated by WFTSFs was widely acknowledged during this time along with seasonal coughs and impaired vision among cooks. Some respondents mentioned that they tried to reduce these problems by moving away from the cooking area and returning when smoke was less visible. Others expressed both a dislike of and concern about smoke but felt compelled to put up with it as food needed to be prepared and they couldn't afford cleaner cooking systems:

"I do not have any means to reduce smoke...and we cannot stop cooking” (Female. Interview. BS-U).

“... it is not my desire to cook on a three-stone fire because of smoke but I have to cook in this way since I do not have alternatives and we have to cook a large quantity of food"

(Female. FGD. BS-PU).

Outside the rainy season, HAP-related health concerns, insofar as they were understood and articulated, tended to be further 'backgrounded' [11,51] in relation to more immediate priorities associated with meeting household food and financial requirements. To some extent this reflects limited awareness of HAP-related health risks coupled with difficulties linking HAP to respiratory problems like chronic obstructive pulmonary disease that are not experienced immediately $[19,54,64]$.

\subsection{The influence of economic factors}

As the quotes above suggest, economic constraints and associated spending priorities had a significant influence on stove and fuel choices in the study area. Providing some support for the energy ladder model [28], FGDs indicated that low income groups tended to rely particularly heavily on WFTSFs; especially in BS-R and BS-PU where zero-cost fuelwood was available:

"Just look around this community...you will discover that it is poorer households that travel in search of firewood"

(Female. Interview. BS-PU).

By contrast, higher income groups ${ }^{3}$ in all three sites and residents of BS-U (who typically purchased their firewood) tended to make greater use of modern and transitional fuel/stove combinations including electric, gas and kerosene. As other studies suggest [14,20-22,30-33], a key barrier amongst non-adopters in BS-U seemed to be the initial cost of a clean stove ${ }^{4}$ rather than concerns about ongoing fuel costs. Indeed, respondents in BS-U in particular were aware that a $5 \mathrm{~kg}$ LPG cylinder typically cost US $\$ 6^{5}$ and would usually last a family of four for a month, making its cost comparable to the charcoal needed to fuel an Abacha stove:

"I am aware that after the preliminary cost of the stove, the users only need to refill the gas cylinder and that now has a lower operational cost compared to kerosene, charcoal and firewood...Nevertheless we have other needs that constrain our budget"

(Male. Interview. BS-U).

In support of studies indicating low levels of demand for CCS $[1,9,10,14,21]$, discussions about competing spending priorities indicated preferences to invest in children's education, land/property and goods (e.g. generators or a vehicle) that would help in developing or expanding businesses:

"I cannot make such investment because I need to pay my children"s tuition fees and expand my firewood business"

(Male. FGD. BS-R).

These preferences were particularly pronounced in BS-R and BS-U where many households depended heavily on zero-cost fuelwood. Reflecting particularly low concern for (or 'backgrounding') of HAPrelated health risks coupled with the low aspirational value of CCS relative to property-based assets, some respondents stated that they would prioritise a new kitchen over a new stove as they perceived wellventilated kitchens to be more effective in reducing smoke.

For users that had already invested in transitional or clean cooking solutions, by contrast, rising fuel costs coupled with fluctuating household incomes sometimes resulted in either temporary or longerterm backsliding. In terms of longer-term backsliding, many households that had previously stacked kerosene stoves reported abandoning them in favour of WFTSFs as they found it hard to obtain kerosene at the official subsidised price of US $\$ 0.25 /$ litre. This became more pronounced in BR-U after the subsidy was removed in January 2016 and the official price rose to US $\$ 0.41$ [58]. In the study area, kerosene was commonly sold for US\$1.05-1.7/litre which was considered too expensive for regular use as a cooking fuel:

“...kerosene...is available only at the unregulated price of $\$ 210$ [US $\$ 1.05]$ even in urban areas so some of us are forced to use three-stone fireplaces. Sometimes we wonder if it is the government's desire to encourage us to use firewood"

(Male. FGD. BS-R).

Shorter term shifts between cooking stack elements tended to reflect efforts to juggle user-based cooking priorities, available income and a

\footnotetext{
${ }^{3}$ Income groups in the study sites were identified using a range of indictors including the number of income-earners in the household, their approximate income levels and key household expenses including the average cost of household energy.

${ }^{4}$ Gas stove prices started from US\$63 while a double burner electric stove cost US\$105. Kerosene stoves cost around US\$40 compared to US\$15 for an Abacha stove.

${ }^{5}$ US\$1 equated to around 200 Nigerian Naira in May 2015
} 
need to minimise the risk of not being able to cook:

"I like charcoal, I use it when I do not have money to refill my gas cylinder and when I do not have the charcoal, I use firewood and with these three arrangements, I rarely run out of fuel for cooking household food"

(Female elder. Interview. BS-U).

“...[the] electric stove, has high electricity bills associated with it. I can't afford continuous usage and the price of kerosene too is high but the Abacha stove is okay given my lean resources"

(Female. FGD. BS-U).

Providing additional insights into seasonal shifts towards cleaner cooking stack components, FGDs revealed that fuelwood price rises during the rains worked alongside increased smoke and wet cooking locations to encourage the temporary abandonment of WFTSFs among households that paid for their wood. Because of higher transport costs in the wet season, prices were reported as being over US $\$ 15$ for a month's supply compared to US $\$ 10$ in the dry season. Seasonal price variations were also reported for charcoal with a $100 \mathrm{~kg}$ bag in the wet season typically costing US\$8 in BS-U and US\$6 in BS-PU compared to dry season prices of US\$6 in BS-U and US\$5 in BS-PU. ${ }^{6}$

Although these price differences didn't appear to inhibit a shift to Abacha stoves during the rains - even in BS-R where many households gathered fuelwood free of cost - households with gas stoves tended to make greater use of them in the rainy season.

\subsection{The influence of factors related to fuel access and quality of service}

In addition to cost-related factors, issues relating to access and quality of service often discouraged the adoption of clean (or cleaner) cooking technologies or - where households already owned such technologies - their sustained use. Likewise, the role of stacking in minimising risks associated with fuel price fluctuations applied equally to short and longer-term fuel access problems.

In BS-R and BS-PU, the availability of free fuelwood and the time taken to gather it had a major influence on the composition of household cooking stacks. A number of respondents from these sites lamented their declining access to firewood but felt financially constrained in paying for alternative fuels. This was particularly noticeable in BS-PU where the conversion of former forest and bush into farm land had made fuelwood collection more time-consuming:

"Since firewood around the community has been exhausted, we travel to the hinterland covering $10 \mathrm{~km}$ each trip...valuable time that could have been invested in other household activities is lost in the process, but firewood is obtained at a free cost"

(Female. FGD. BS-PU).

Alternative fuel options were limited, however, as access to electricity connections and LPG infrastructure was poor and kerosene was rarely available in BS-R.

In BS-U, by contrast, the lack of access to free firewood meant that wood-fuelled stoves occupied a less prominent place within household cooking stacks while better access to electricity, kerosene, LPG and associated infrastructure encouraged the use of transitional and clean cooking systems. Nevertheless, concerns about poor quality of service were reported to have hindered the adoption and use of electric stoves due to suspicions about corruption surrounding estimated (rather than metered) electricity billing. This was most common in BS-PU and BS-U where electricity meters were uncommon:

${ }^{6} \mathrm{~A} 100 \mathrm{~kg}$ bag typically lasted a family of five for one month. "many people protested because there were no electric meters to read their daily consumption"

(Female Elder. Interview. BS-U).

For other respondents, concerns about the quality of the electricity supply were more significant in discouraging the adoption of electric cookers or causing backsliding among households that owned them. Echoing Oyedepo's [8] critique of Nigeria's failure to meet domestic demand for electricity, FGDs highlighted a decline in the regularity and reliability of their service:

"Although I bought an electric stove about three years ago, we hardly have steady electricity supply in our community... When they supply electricity, it lasts few hours, so we do not use the stove"

(Male elder. Interview. BS-U).

The difficulties associated with re-filling LPG cylinders were also reported as causes of backsliding in BS-PU as the need to travel to BS-U for this added significant expenditure:

"I have a gas stove, though I stopped using it because of the refilling, transportation charges...I now use my Abacha stove"

(Female. FGD. BS-PU).

In BS-U where access to LPG and kerosene (albeit not at the official price) was better than in BS-PU and BS-R, households relied on WFTSFs when these fuels were in short supply. For kerosene, shortages tended to occur in the dry season as demand was lower and vendors didn't always maintain their supplies. This facilitated seasonal fuel switching as households made greater use of kerosene in the wet season when fuelwood was hard to access, smoky and difficult to light. Similar tendencies were also apparent among electric stove users who were forced by seasonal supply interruptions to backslide to transitional or biomass fuels:

“...there will be a need to make alternative arrangements since electricity supply has been seasonal over time. In such situations, the traditional stove has a role to play that is very essential"

(Male. Interview. BS-U).

In BS-R, by contrast, options for seasonal re-stacking were more limited as kerosene was rarely available and wet weather conditions made firewood collection difficult. For households wishing to avoid using WFTSFs during this period, charcoal-fuelled Abacha stoves were generally regarded as the most accessible and reliable option.

\section{Discussion}

Findings from the study sites illustrate how end-user cooking preferences and priorities are spatially and temporally specific and often differ widely from more technology-oriented systems for classifying improved cooking systems [37,42]. As Benue is poorly serviced with energy infrastructure - particularly outside urban areas - these preferences and priorities are intersected by variations in the cost of and access to different fuels and cooking devices. In contrast to fuel efficiency as an incentive for CCS adoption and sustained use [30] competing economic priorities coupled with seasonal and rural-urban variations in fuel prices, access and reliability of supply acted as more important influences on stove and fuel use decisions in the study area (see Fig. 3).

Echoing critiques of the energy ladder model [14,16,20,24,28,29], income was often not the most significant influence on cooking system choices. As is the case in high income countries, fuel/stove stacking was widely undertaken to facilitate varied (and socio-culturally specific) cooking practices whilst minimising fuel insecurity risks by enabling flexible responses to fluctuations in fuel costs, accessibility and reliability of supply [14,24]. Reflecting this, both backsliding and more temporary (often seasonal) shifts away from clean and transitional fuels were quite common among (primarily urban) households when faced 
Risk perceptions

(Seasonal) backgrounding HAP risks

Foregrounding fuel security

Fears of kerosene burns/explosions

Fears of LPG explosions
Access

Poor energy infrastructure

Seasonal fuel shortages

Seasonal electricity interruptions

Seasonal firewood gathering

Economic

Stove price,

Zero-cost biomass

Ongoing fuel costs

Fuel price rises

Seasonal price variations

Competing household needs
Socio-cultural and utilitarian

Smoke for food preservation

Smoke signals social status

Preferred taste of food

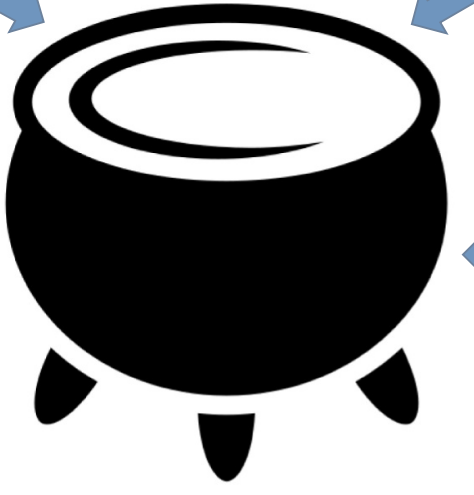

acceptability of fuelling

Ease of fuelling

Stove size and capacity

Sooty pots from biomass

Smoke nuisance in rainy season

Wood hard to light when wet

Stove durability and reliability

Fig. 3. Key influences on cooking system choices.

with rising prices or reduced/unreliable access to their preferred fuels. Backsliding was also linked to families 'outgrowing' their improved stoves and reverting to WFTSFs which allowed them to cook larger meals.

Of significance for initiatives seeking to promote CCS transitions was the value placed by households from all three sites and across income groups on retaining WFTSFs within their cooking stacks. In rural areas where fuelwood could be freely gathered, cost and accessibility considerations were clearly important, but this was less true of urban households that had access to a range of alternative fuels but were frequently willing to pay more for firewood. Echoing findings by Herington et al. and Malakar et al. [20-22], this inertia reflected the interplay of social systems and energy services (including particular stove/fuel characteristics) on the practice of cooking. Particularly important were 'ethnic-specific' [10] cultural preferences for food cooked using biomass and the capacity of WFTSFs to cook large quantities which in the study area signals food security and wealth. In more practical terms, WFTSFs were valued for their sturdiness, reliability, simplicity and flexibility (in accepting unprepared fuelwood and different sized pots) as well as for producing smoke for preserving food. These characteristics coupled with difficulties in accessing CCS that are perceived as reliable, flexible, affordable and safe present important challenges for stimulating their adoption and sustained used; particularly in rural areas where zero-cost firewood is available.

Reflecting Smith and Ezzati's (2005, p. 324) finding that 'high effective discount rates' tend to accompany low incomes, discussions of HAP-related health risks indicated that many respondents were forced to 'background' $[11,51]$ these relative to more pressing anxieties linked to food and financial security and the need to ensure some means of cooking. Although some respondents had experienced serious HAP-related illnesses, others struggled to connect smoke to diseases with temporally distant symptoms and, following various accidents in the local community, expressed greater concern about risks linked to kerosene burns, stove explosions and leakages from highly flammable LPG cylinders.

Nevertheless, evidence from BS-R and BS-PU indicated that a desire to avoid smoke produced by wet fuelwood coupled with difficulties in gathering wood during the rainy season sometimes stimulated seasonal shifts from WFTSFs to slightly cleaner and more efficient charcoal stoves. As most respondents appeared to be acting in response to discomfort rather than an awareness of HAP-related health risks, it is possible that such shifts could be encouraged through information and communication campaigns targeting respiratory health or greater involvement of women (as change agents or CCS entrepreneurs) within the CCS value chain [44].

\section{Conclusions}

The challenges of increasing demand for cleaner fuels and improved stoves among low income biomass-dependent groups are increasingly acknowledged [1,7,9,10,12,20,65]; especially in rural areas where zero-cost fuelwood is available and national energy policies overlook its importance as an energy source [38]. While findings from this study are drawn from three communities in Nigeria and can't be generalised to other regions or countries, they nevertheless shed light on decisions underpinning cooking system choices that are likely to resonate with biomass-dependent groups in other parts of the world. In particular, our research illustrates how end-users favour stacking a range of stoves and fuels that give them the flexibility to cook different foods for varying numbers of people whilst minimising risks related to changes in price, accessibility and reliability of different fuels along with perceived safety hazards. Whilst efforts to discourage stacking would be counterproductive and most probably resisted, an emphasis on promoting cleaner and safer stacks may be more effective in combining end-user priorities with health and environmental benefits.

In particular, more emphasis on risk perceptions within CCS promotion and social marketing initiatives would help to elucidate userdefined benefits of different cooking stack components and factors underlying variations in stack composition over time and space [9]. The influence of reliability of supply, sustainability and affordability of household energy sources on CCS use is recognised by SE4ALL and included in SDG7 indicators [65]. Keeping track of their impacts on cooking system use is problematic, however, as household-level data is currently limited on the nature of cooking technologies used [1] and household surveys rarely capture information on seasonal changes in fuel or stove use. Particularly problematic is the focus of most household data collection to date on the 'main' cooking fuel rather than whether multiple fuels or stoves are used. This provides a poor sense of trends in fuel stacking and 'backsliding' over time (including seasonally) and space. Given that SDG7.1.2's indicator is the 'proportion of the population with primary reliance on clean fuels and technologies' (our emphasis), limited data is likely to be collected on the nature of household fuel and stove 'stacks' - and how they vary spatially between rural, peri-urban and urban contexts or temporally. This will in turn provide an incomplete picture of HAP exposure and the success of measures taken to reduce this. 
In terms of developing monitoring and evaluation tools to 'support sustained success of HAP interventions' [13:5], it would be useful to track the components of household fuel and stove stacks as well as more linear shifts between the main fuels and stoves used. This would enable better insights to be gained on how the components of stove and fuel stacks vary in different settings and over shorter as well as longer time periods. It also has potential to encourage initiatives promoting cleaner stacks that allow households flexibility to adjust to fluctuating fuel prices, availability, reliability or changing family sizes whilst seeking to prevent backsliding. While the establishment of such a nuanced monitoring approach would no doubt be complex, the development of tiered approaches to monitoring multiple attributes of energy access suggests that it is possible [1].

In terms of encouraging shifts to cleaner stacks that make greater use of fuels like electricity and LPG, there may be useful lessons to learn from community-wide behaviour change approaches used in sanitation interventions $[9,19]$. In particular, multi-level approaches embodying sensitivity to culturally-rooted end-user priorities and risk perceptions could help to encourage community-level shifts in the adoption and sustained use of cleaner cooking technology stacks; especially if combined with financing strategies and infrastructural investment to address affordability and quality of service constraints.

\section{Declaration of Competing Interest}

The authors declare that they have no known competing financial interests or personal relationships that could have appeared to influence the work reported in this paper.

\section{Acknowledgements}

This work was supported by the Government of Nigeria's Tertiary Education Trust [TETFUND/ES/AST\&D/POLY/UGBOKOLO/VOL.XIV] and a Department for International Development, Department of Energy and Climate Change, and Engineering and Physical Sciences Research Council joint grant [EP/L002639/1]. We would like to thank Esther Igyase for working alongside Atagher during his field research as well as respondents in the study communities without whose assistance the research would not have been possible. The authors are also very grateful to the anonymous reviewers whose comments and suggestions were extremely useful in improving the paper Supplementary materials

\section{Supplementary material}

Supplementary material associated with this article can be found, in the online version, at doi:10.1016/j.erss.2019.101340.

\section{References}

[1] IEA (International Energy Agency), International Renewable Energy Agency, United Nations Statistics Division, World Bank Group, World Health Organisation, International Bank of Reconstruction and Development, Washington, DC, 2018 Tracking SDG7. The Energy Progress Report 2018.

[2] S.O. Oyedepo, On energy for sustainable development in Nigeria, Renew. Sustain. Energy Rev. 16 (2012) 2583-2598.

[3] ICEED (International Centre for Energy Environment and Development), 120 million Nigerians especially women, vulnerable to dangers of firewood smoke, Available: (2019) http://iceednigeria.org/ic/120-million-nigerian-womenvulnerable-to-dangers-of-firewood-smoke-expert/.

[4] B.K. Sovacool, The political economy of energy poverty: a review of key challenges, Energy Sustain. Develop. 16 (3) (2012) 272-282, https://doi.org/10.1016/j.esd. 2012.05.006.

[5] R. Listo, Gender myths in energy poverty literature: a critical discourse analysis, Energy Res. Soc. Sci. 38 (2018) 9-18, https://doi.org/10.1016/j.erss.2018.01.010.

[6] K.R. Smith, M. Jerrett, H.R. Anderson, R.T. Burnett, V. Stone, R. Derwent, Public health benefits of strategies to reduce greenhouse-gas emissions: health implications of short-lived greenhouse pollutants, Lancet 374 (2009) 2091-2103.

[7] WHO, Burning opportunity: Clean Household Energy for health, Sustainable development, and Wellbeing of Women and Children, WHO, Geneva, 2016.
[8] GACC. About. Available: (2017) http://cleancookstoves.org/about/.

[9] T. Sesan, S. Jewitt, M. Clifford, C. Ray, Toilet training: what can the cookstove sector learn from improved sanitation promotion? Int. J. Environ. Health Res. 28 (2018) 667-682

[10] A. Akintan, S. Jewitt, M. Clifford, Culture, tradition, and taboo: understanding the social shaping of fuel choices in Nigeria, Energy Res. Soc. Sci. 40 (2018) 14-22.

[11] S. Jewitt, K. Baker, Risk, wealth and agrarian change in India: Household-level hazards vs. late-modern global risks at different points along the risk transition, Glob. Environ. Chang. 22 (2012) 547-557.

[12] M. Jürisoo, F. Lambe, M. Osborne, Beyond buying: the application of service design methodology to understand adoption of clean cookstoves in Kenya and Zambia, Energy Res. Soc. Sci. 39 (2018) 164-176, https://doi.org/10.1016/j.erss.2017.11. 023.

[13] J. Rosenthal, K. Balakrishnan, N. Bruce, D. Chambers, J. Graham, D. Jack, et al., Implementation science to accelerate clean cooking for public health, Environ. Health Perspect. 125 (2018) 3-7.

[14] O.R. Masera, B.D. Saatkamp, D.M. Kammen, From linear fuel switching to multiple cooking strategies: a critique and alternative to the energy ladder model, World Dev. 28 (2000) 2083-2103.

[15] B. Van Der Kroon, R. Brouwer, P.J. Van Beukering, The energy ladder: theoretical myth or empirical truth? results from a meta-analysis, Renew. Sustain. Energy Rev. 20 (2013) 504-513.

[16] I. Ruiz-Mercado, O. Masera, Patterns of stove use in the context of fuel-device stacking: rationale and implications, Ecohealth 12 (2015) 42-56.

[17] M.U. Treiber, L.K. Grimsby, J.B. Aune, Reducing energy poverty through increasing choice of fuels and stoves in Kenya: complementing the multiple fuel model, Energy Sustain. Develop. 27 (2015) 54-62.

[18] S. Jewitt, A. Mahanta, K. Gaur, Sanitation Sustainability, Seasonality and Stacking: Improved facilities for how long, where and whom? Geogr. J. 184 (2018) 255-268.

[19] T. Clasen, K.R. Smith, Let the "A" in wash stand for air: integrating research and interventions to improve household air pollution (HAP) and water, sanitation and hygiene (WaSH) in low-income settings, Environ. Health Perspect. 127 (2019), https://doi.org/10.1289/EHP4752.

[20] Y. Malakar, C. Greig, E. van de Fliert, Resistance in rejecting solid fuels: beyond availability and adoption in the structural dominations of cooking practices in rural India, Energy Res. Soc. Sci. 46 (2018) 225-235, https://doi.org/10.1016/j.erss. 2018.07.025.

[21] Y. Malakar, Studying household decision-making context and cooking fuel transition in rural India, Energy Sustain. Develop. 43 (2018) 68-74, https://doi.org/10. 1016/j.esd.2017.12.006.

[22] M.J. Herington, P.A. Lant, S. Smart, C. Greig, E. van de Fliert, E. Defection, recruitment and social change in cooking practices: energy poverty through a social practice lens, Energy Res. Soc. Sci. 34 (2017) 272-280, https://doi.org/10.1016/j. erss.2017.09.001.

[23] C. Bielecki, G. Wingenbach, Rethinking improved cookstove diffusion programs: a case study of social perceptions and cooking choices in rural Guatemala, Energy Policy 66 (2014) 350-358.

[24] A. Jagadish, P. Dwivedi P, In the hearth, on the mind: cultural consensus on fuelwood and cookstoves in the middle Himalayas of India, Energy Res. Soc. Sci. 37 (2018) 44-51, https://doi.org/10.1016/j.erss.2017.09.017.

[25] M. Khandelwal, M.E. Hill, P. Greenough, J. Anthony, M. Quill, M. Linderman, H.S. Udaykumar, Why have improved cook-stove initiatives in India failed? World Dev. (2016), https://doi.org/10.1016/j.worlddev.2016.11.006xx.

[26] B. Sovacool, What are we doing here? Analyzing fifteen years of energy scholarship and proposing a social science research agenda, Energy Res. Soc. Sci. 1 (2014) 1-29.

[27] B. Sovacool, M. Bazilian, M. Toman, Paradigms and poverty in global energy policy: research needs for achieving universal energy access, Environ. Res. Lett. 11 (2016), https://doi.org/10.1088/1748-9326/11/6/064014.

[28] R.H. Hosier, J. Dowd, Household fuel choice in Zimbabwe: an empirical test of the energy ladder hypothesis, Resour. Energy 9 (4) (1987) 347-361.

[29] G. Leach, The energy transition, Energy Policy 20 (1992) 116-123.

[30] E.A. Rehfuess, E. Puzzolo, D. Stanistreet, D. Pope, N.G. Bruce, Enablers and barriers to large-scale uptake of improved solid fuel stoves: a systematic review, Environ. Health Perspect. 122 (2014) 120-130, https://doi.org/10.1289/ehp.1306639.

[31] D. Stanistreet, E. Puzzolo, N. Bruce, D. Pope, E. Rehfuess, Factors influencing household uptake of improved solid fuel stoves in low- and middle-income countries: a qualitative systematic review, Int. J. Environ. Res. Public Health 11 (8) (2014) 8228-8250, https://doi.org/10.3390/ijerph110808228.

[32] Y. Wang, R. Bailis R, The revolution from the kitchen: social processes of the removal of traditional cookstoves in Himachal Pradesh, India, Energy Sustain. Develop. 27 (2015) 127-136, https://doi.org/10.1016/j.esd.2015.05.001.

[33] E. Puzzolo, D. Pope, D. Stanistreet, E.A. Rehfuess, N.G. Bruce, Clean fuels for resource-poor settings: a systematic review of barriers and enablers to adoption and sustained use, Environ. Res. 146 (2016) 218-234, https://doi.org/10.1016/j. envres.2016.01.002.

[34] A. Kar, H. Zerriffi H, From cookstove acquisition to cooking transition: framing the behavioural aspects of cookstove interventions, Energy Res. Soc. Sci. 42 (2018) 23-33, https://doi.org/10.1016/j.erss.2018.02.015.

[35] G.L. Simon, Geographies of mediation: market development and the rural broker in Maharashtra, India, Polit Geogr. 28 (2009) 197-207.

[36] T.A. Sesan, Navigating the limitations of energy poverty: lessons from the promotion of improved cooking technologies in Kenya, Energy Policy 47 (2012) 202-210.

[37] T.A. Sesan, Global imperatives, local contingencies: an analysis of divergent priorities and dominant perspectives in stove development from the 1970s to date, Progr. Develop. Stud. 14 (2014) 3-20.

[38] D. Barnes, S.R. Khandker, H.A. Samad, 'Energy poverty in rural Bangladesh, Energy 
Policy 39 (2011) 894-904.

[39] B. Person, J.D. Loo, A.L. Cohen, It is good for my family's health and cooks food in a way that my heart loves: qualitative findings and implications for scaling up an improved cookstove project in rural Kenya, Int. J. Environ. Res. Public Health 9 (2012) 1566-1580.

[40] N.D. Moses, N.A. MacCarty, What makes a cookstove usable? trials of a usability testing protocol in Uganda, Guatemala, and the United States, Energy Res. Soc. Sci. 52 (2019) 221-235, https://doi.org/10.1016/j.erss.2019.02.002.

[41] K.R. Smith, Why both gas and biomass are needed today to address the solid fue cooking problem in India: a challenge to the biomass stove community, Energy Sustain. Develop. 38 (2017) 102-103.

[42] K. Troncoso, A. Castillo, O. Masera, L. Merino, Social perceptions about a technological innovation for fuelwood cooking: case study in rural Mexico, Energy Policy 35 (2007) 2799-2810.

[43] P.P. Otte, A (new) cultural turn toward solar cooking-Evidence from six case studies across India and Burkina Faso, Energy Res. Soc. Sci. 2 (2014) 49-58, https://doi.org/10.1016/j.erss.2014.04.006.

[44] T. Sesan, M. Clifford, S. Jewitt, C. Ray, 'We learnt that being together would give us a voice': gender perspectives on the East Africa improved cookstove value chain, Fem. Econ. (2019), https://doi.org/10.1080/13545701.2019.1657924.

[45] E. Fingleton-Smith, The lights are on but no (men) are home. The effect of traditional gender roles on perceptions of energy in Kenya, Energy Res. Soc. Sci. 40 (2018) 211-219.

[46] A. Giddens, The Constitution of Society: Outline of the Theory of Structuration, Polity, Cambridge, 1984.

[47] N.J. Goodwin, S.E. O'Farrell, K. Jagoe, J. Rouse, E. Roma, A. Biran, E.A. Finkelstein, Use of behavior change techniques in clean cooking interventions: a review of the evidence and scorecard of effectiveness, J. Health Commun. 20 (Suppl. 1) (2015) 43-54, https://doi.org/10.1080/10810730.2014.1002958.

[48] D. Hernández, E. Siegel, Energy insecurity and its ill health effects: a community perspective on the energy-health nexus in New York city, Energy Res. Soc. Sci. 40 (2019) 211-219.

[49] M. Cordoves-Sánchez, A. Vallejos-Romero, Social construction of risk in non-conventional renewable energy: risk perception as a function of ecosystem services in La Araucanía, Chile, Ecol. Econ. 159 (2019) 261-270.

[50] D.A. Wadley, J.H. Han, P.G. Elliott, Risk hidden in plain sight: explaining homeowner perceptions of electricity transmission infrastructure, Energy Policy 132 (2019) 744-753.
[51] M. Douglas, A. Widalsky, Risk and Culture: An Essay On the Selection of Technological and Environmental Dangers, University of California Press, Berkeley and Los Angeles, 1982.

[52] A.H. Maslow, Motivation and Personality, second ed, Harper and Row, New York, 1970.

[53] K.R. Smith, The risk transition and developing countries, in: J.X. Kasperson, R. Kasperson (Eds.), Global Environmental Risk, Earthscan, London, 2001, pp. $148-172$.

[54] K.R. Smith, M. Ezzati, How environmental health risks change with development: the epidemiologic and environmental risk transitions revisited, Ann. Rev. Environ. Resour. 30 (2005) 291-333.

[55] R. Olorunbi, The Rising Cost of Nigeria's Petroleum Subsidy, (2019) The Africa Report. 15/01/2019. Available https://www.theafricareport.com/418/nigeria-thecost-of-cheaper-petrol/.

[56] S. Opera, 90 Per Cent of Nigerian Homes Lack LPG Cylinders, Reveals NLPGA, The Guardian, 2018 21/11/18. Available https://guardian.ng/energy/90-per-cent-ofnigerian-homes-lack-lpg-cylinders-reveals-nlpga/.

[57] C. Agbaegbu, M. Amaza, Black market and middlemen — not poor — benefit from kerosene subsidy. Available (2018): https://www.icirnigeria.org/black-marketand-middle-men-not-poor-benefit-from-kerosene-subsidy/ Accessed 30/04/19.

[58] IISD, Compensation mechanisms for fuel subsidy removal in Nigeria. Available (2016): https://www.iisd.org/sites/default/files/publications/compensationmechanisms-fuel-subsidy-removal-nigeria.pdf.

[59] Punch, keroene subsidy removal. A boost for cooking gas. 29/01/19. Available (2019): https://punchng.com/kerosene-subsidy-removal-a-boost-for-cooking-gasadeshina/.

[60] M. Beard, An exploration of the factors associated with paediatric burn injuries in rural and peri-urban Malawi, PhD thesis University of Nottingham, 2017.

[61] A. Bryman, Social Research Methods, fifth ed., Oxford University Press, USA, 2016.

[62] B.K. Sovacool, J. Axsen, S. Sorrell, Promoting novelty, rigor, and style in energy social science: towards codes of practice for appropriate methods and research design, Energy Res. Soc. Sci. 45 (2018) 12-42, https://doi.org/10.1016/j.erss.2018. 07.007 .

[63] J. Smithson, Focus Groups, SAGE Publications, London, UK, 2008.

[64] K. Ravindra, K.R. Smith, Better kitchens and toilets: both needed for better health, Environ. Sci. Pollut. Res. 25 (2018) 12299-12302, https://doi.org/10.1007/ s11356-018-1879-4p.

[65] SE4ALL, Available (2018): https://www.seforall.org/heatmaps/cleancooking. 